Pediat. Res. 13: 725 (1979)

\title{
Public Acceptability of Vaccine
}

\author{
ANTHONY J. MORRIS
}

DR. MORRIS REQUESTED TIME TO MAKE THE FOLLOWING PRESENTATION

The title of this conference is "A Symposium on Public Concerns of Immunization."

Some time has been spent during this symposium on the question of public acceptability of vaccines. Numerical data presented by the Center for Disease Control (CDC) at this meeting suggest that public acceptance of vaccines is not now a problem nor is the public conception of the value derived from the use of vaccines a problem. Therefore, according to CDC data, acceptance of vaccines and the value derived from their use are not now areas of "public concerns." However, the occurrence of Guillain-Barre syndrome (GBS) and the occurrence of other serious adverse reactions after use of swine-flu vaccine are current issues of public concern-so much so, that Mr. Joseph Califano, secretary of the Department of Health, Education and Welfare, responded to a question asked in a recent press conference by saying that several hundred cases of GBS and 120 deaths have been, at least, temporally associated with the adminstration of swine-flue vaccine. The fact that the secretary of DHEW was asked this question at a press conference is an indication that the occurrence of GBS and death in swine-flu vaccines in a setting that related GBS and death temporally to the administration of the swine-flu vaccine are areas of public concern. Yet, during a day and a half of this symposium, neither of these areas was discussed.

I would like to make a brief comment on one of Dr. Karzon's statements. Dr. Karzon mentioned that if uncertainty is a characteristic of much of our knowledge of vaccines and of vaccine usage it might be well not to make these uncertainties public information; these uncertainties might confuse the public. It is my position that if it is a fact that uncertainty is a characteristic of much of our knowledge of vaccines and of vaccine usage, then the public should be the first to know of this, and the public should be told of those areas in which there is a marked degree of uncertainty in our knowledge and the public should also be told of those areas in which there is a marked degree of certainty in our knowledge.

I would like now to make a brief comment on Dr. Melnick's statement concerned with the value of public hearings on issues of public interest. Recently, the House of Representatives subcommittee on appropriations for the Department of Health, Education

\section{DISCUSSION}

The rejoinder to Dr. Morris' comments include the following: The question of liability associated with the Swine Flu vaccine program is not yet resolved. The Congress is currently faced with more than one billion dollars in suits against the government in this regard. In addition, none of the recommendations of the National Immunization Conference have been implemented. It is disconserting that no action has yet been taken towards the implementation of these recommendations to date. The public has a right to know the reason why this is so.

It was suggested that full disclosure regarding the risk/benefit effects of vaccines should be available to the public. It should be made clear that no immunization is $100 \%$ safe to $100 \%$ of the population. The possible probability of known potential risks and benefits of receiving the vaccine must be identified both in the case of an individual and the society at large.

It was pointed out by a CDC representative that the information form developed for the current influenza vaccine program presents and Welfare held hearings on a proposed program to vaccinate against an expected outbreak of influenza in the winter of 197879. Those who proposed the program were heard and those who opposed the program were heard, after which the subcommittee voted not to fund the program. After this rejection, a Senate subcommittee also voted not to fund the program. However, on the floor of the Senate and at the urging of a single senator, a vote was taken that approved funding of the vaccination program at approximately one-half the amount of money (\$8.2 million) requested ( $\$ 15$ million). The program was finally funded by the Congress at the $\$ 8.2$ million level.

The concerns discussed and argued before the committees and subcommittees of the Congress and presented to the full House of Representatives and to the Senate on public funding for vaccine programs, are areas of great public concern. None of these was discussed at this symposium.

Dr. Foege of the CDC in April of 1978 testified before the House of Representative subcommittee on appropriations in defense of the requested \$15 million to fund the proposed influenza vaccination program for the winter of 1978-79. Dr. Foege also testified in April of 1978 before the Senate's subcommittee on appropriations in defense of the requested \$15 million. First, Dr. Foege gave one figure for deaths to be expected from Russian flu before one subcommittee and another figure before the other subcommittee. In the least, Dr. Foege's testimony was misleading. Second, the Department of Health, Education and Welfare was asked by the Congress to provide information on the swine-flu vaccination program before the vote to fund the Russian flu program. This information was to be delivered, I believe, to the Congress in September of 1977. This promised information was still not delivered in April of 1978. In my judgment, this kind of behavior on the part of physicians and scientists before the Congress was partly responsible for the vote by the subcommittees of Congress not to fund the Russian flu program and for the vote of the full houses of Congress to reduce by approximately one-half the requested amount of money. In my judgment, it is this kind of behavior on the part of public health officials which is an issue of public concern.

the potential risk associated with the influenza vaccine. It notes, in fact, that the vaccine is not $100 \%$ effective.

The value of Congressional hearings which provide a forum for consumers to express their concerns or support was pointed out. This, however, did not mean that Congressional decisions will always reflect those points of view expressed by consumers or any other groups because as in any decision making process, the Congressional decisions are also subject to competing claims and political priorities.

The need for developing effective strategies to reach the public and present the information in a balanced fashion was pointed out. In complex issues such as the risk/benefit question on vaccinations, it becomes very difficult to present a balanced picture without either causing undue alarm or suggesting complete safety. This is an area which requires additional research and much understanding. 